\title{
Potenciais cooperativos do podcast escolar por uma perspectiva freinetiana
}

\author{
EUGÊNIO PACCELLI AGUIAR FREIRE \\ Universidade Federal do Rio Grande do Norte, Natal, RN, Brasil
}

RESUMO

Este artigo investiga se o uso de podcast no Brasil segue a concepção cooperativa de Célestin Freinet (1998), para quem a cooperação é uma ação educativa conjunta, motivada pelo interesse espontâneo e envolta em uma atmosfera livre. Confirmada a hipótese examinada, o referencial freinetiano servirá como alicerce para a elaboração de referenciais educativos para o desenvolvimento de podcasts cooperativos escolares a partir da apropriação, contextualizada à educação formal, das relações produtivas vistas na podosfera brasileira, examinadas por meio de uma observação participante on-line. Esse procedimento será precedido da apresentação da tecnologia tratada, bem como da elucidação dos parâmetros teórico-metodológicos desta pesquisa. Como resultado desses procedimentos, foi elaborado um conjunto de referenciais para projetos que busquem trabalhar a cooperação freinetiana por meio do podcast na educação formal.

PALAVRAS-CHAVE

cooperação em Freinet; tecnologia de oralidade; oralidade digital; Freinet. 


\title{
SCHOOL PODCAST'S COOPERATIVE POTENTIALS IN A FREINET'S PERSPECTIVE
}

\begin{abstract}
This paper investigates the use of Brazilian podcasts and follows the cooperative design of Célestin Freinet (1998), for whom cooperation is a joint educational activity motivated by spontaneous interest and engulfed in a free atmosphere. Confirming the hypothesis examined, the Freinet's perspective will serve as a base for development of educational frameworks for the development of cooperative educational podcasts from the appropriation, contextualized to formal education, of the productivity seen in Brazilian podosphere relations, examined from on-line participant observation. This procedure will be preceded by the presentation of the technology in question as well as the elucidation of the theoretical and methodological parameters of this research. As a result of these procedures, a set of references for projects that seek to work Freinet's cooperation through the podcast in formal education was prepared.
\end{abstract}

\section{KEYWORDS}

cooperation in Freinet; orality technology; digital orality; Freinet.

\section{POTENCIALES PARTICIPATIVOS DEL PODCAST ESCOLAR PARA UNA PERSPECTIVA FREINETIANA}

\section{RESUMEN}

En este trabajo se investiga el uso del podcast en Brasil siguiendo el diseño participativo de Célestin Freinet (1998), para quien la participación es una acción educativa conjunta motivada por el interés espontáneo y envuelto en una atmósfera de libertad. Confirmada la hipótesis examinada, el marco freinetiano servirá de base para el desarrollo de marcos educativos para el desarrollo de podcasts escolares participativos a partir de la propiedad, contextualizados para la educación formal, las relaciones productivas vistas en las relaciones con el universo de podcasts brasileños, examinados por los participantes desde una perspectiva on-line. Este procedimiento será precedido por la presentación de la tecnología a tratar, así como el esclarecimiento de los parámetros teóricos y metodológicos para esta investigación. Como resultado de estos procedimientos, fue elaborado un conjunto de referencias para proyectos que buscan trabajar con una participación freinetiana través del podcast en la educación formal.

\section{PALABRAS CLAVE}

cooperación em Freinet; tecnología de la oralidad; oralidad digital; Freinet. 


\section{INTRODUÇÃO}

Considerando-se o entendimento de Paulo Freire (1971), para o qual a educação não se resume à escolarização, observa-se que, na prática que ocorre fora dos bancos escolares, o uso brasileiro de uma tecnologia recente poderia configurar uma nova esfera educativa. Faz-se referência ao podcast, tecnologia que consiste em um "modo de produção/disseminação livre de programas distribuídos sob demanda e focados na reprodução de oralidade, também podendo veicular músicas/sons" (Freire, 2013a, p. 47). O podcast é geralmente distribuído pela internet por meio de arquivos sonoros MP3, todavia sua modalidade para surdos, que se trata da reprodução parcial da oralidade dos programas por meio da transcrição de suas falas, costuma fazer uso do formato textual PDF (Freire, 2011, p. 203).

A utilização do podcast acarreta a formação do que se designou como "podosfera", ou, em inglês, podosphere. O termo refere-se ao conjunto de produções no âmbito da tecnologia supracitada. Na podosfera do Brasil encontram-se, costumeiramente, práticas nas quais os sujeitos se procuram espontaneamente para a realização de trabalhos em conjunto voltados para a elaboração das produções.

Esse modo de ação constitui-se como um alicerce geral da realização de podcasts no país, o que ocorre em um cenário comumente marcado por "diversas iniciativas de suporte mútuo" (Assis; Salves; Guanabara, 2010, p. 9), bem como pela reunião de esferas produtivas diversas compartilhadas pelos sujeitos - um podcast em geral reúne em seu entorno realizações imagéticas, elaborações textuais em suas postagens em blogs, disposição de links para a ampliação dos temas tratados, entre outros aspectos afins. Além disso, naquele âmbito é comum observar-se a disposição da audiência para realizar ações produtivas com o objetivo de enriquecer o programa que escutam (Freire, 2010, p. 47-48).

Desse modo, a podosfera brasileira emerge como um ponto de encontro para o trabalho em conjunto, motivado pelo compartilhamento entre os sujeitos de interesses afetivos/cognitivos ${ }^{1}$ pelos assuntos abordados nos podcasts. Tais temáticas constituem-se das mais diversas, sendo abordadas por

programas como o "nerdcast", ${ }^{2}$ com temas relacionados, dentre outros, à História, Literatura, Ciências e [...] softwares livres são o tema discutido no "opencast" $3[. .$.$] .$ O "papo de gordo", discutindo questões de obesidade e "dentro do armário", 5 que fala sobre homossexualidade, são apenas mais alguns exemplos que ilustram a diversidade típica do exercício da tecnologia podcast. (Freire, 2012, p. 14)

1 Por "afetivos/cognitivos" faz-se aqui referência ao interesse que, embora se mostre racional pela busca educativa do aprofundamento de um dado tema, constitui-se como uma forte esfera afetiva, já que se relaciona ao prazer proporcionado por um assunto que se insere nas vontades de um sujeito.

2 Disponível em: <jovemnerd.ig.com.br/categoria/nerdcast>. Acesso em: 22 jan. 2013.

3 Disponível em: <www.ubuntero.com.br/feed/opencast >. Acesso em: 22 jan. 2013.

4 Disponível em: <papodegordo.mtv.uol.com.br/tag/podcast>. Acesso em: 22 jan. 2013.

5 Disponível em: <dentrodoarmario.wordpress.com/2011/03/15/podcast-dentro-do-ar ma rio-12>. Acesso em: 22 jan. 2013. 
A diversidade temática constatada nos programas faz com que eles costumem abordar assuntos normalmente ignorados em outros âmbitos tecnológicos, sociais ou mesmo escolares (Freire, 2013c, p. 104). Observa-se, no trabalho de tais temas, a quebra do teor sisudo no tratamento de assuntos vistos usualmente como "duros" (idem, p. 108), a exemplo dos previamente citados que se relacionam a conteúdos curriculares da educação formal.

Os fatores apresentados demonstram o fomento nos usuários da vontade de procurar autonomamente o aprofundamento dos temas abordados (Freire, 2010, p. 48-49), levando os indivíduos a, espontaneamente, tomar uma postura ativa ao realizar pesquisas em busca de mais informações sobre os temas abordados, buscando maior entendimento de tais assuntos. Considerando um pensamento inicial sobre as implicações educacionais da prática supracitada, é pertinente ressaltar que esta ocorre em uma atualidade marcada por um "fabuloso acúmulo da informação em todos os domínios" (Behrens, 2000, p. 71), muito embora, caso tal contexto seja ocupado por indivíduos não afeitos a tomar uma postura de pesquisa, tendem a ser observadas implicações educacionais pouco significativas (Andrade, 2009, p. 7).

Assim, a apresentação das características gerais da podosfera nacional possibilita o entendimento de que esta pode propiciar desenvolvimentos educacionais distantes dos que inúmeras vezes são vistos na esfera da educação formal. Afinal, esta, como aponta Paro (2010, p. 53), encontra-se recorrentemente marcada pelo exercício de ações pautadas por direcionamentos educacionais estritamente coercitivos. Apesar disso, mesmo observando-se comumente esferas escolares seguidoras dos aspectos apontados por Paro, reflexões educacionais revelam que haveria insensatez em uma percepção de que a educação formal seria inapta a contemplar práticas coletivas de caráter centralmente não coercitivo, como as dadas na podosfera brasileira. Afinal, diversos pensadores sustentam a viabilidade do exercício da educação motivado pelo interesse espontâneo dos sujeitos, envolvidos em práticas compartilhadas na quais aqueles detêm um papel ativo, exercido por ações espontâneas (Freire, 1971; Gardner, 1995; Teixeira,1971). Entre os educadores que possuem tal entendimento, pode-se destacar Célestin Freinet.

Em atuação na França entre as décadas de 1920 e 1960, Freinet, ao longo de sua vivência docente em sala de aula, fundou na escola pública de seu país uma pedagogia marcada pela apropriação do trabalho como ação espontânea, coletiva e educacional (Sampaio, 1994). Esta, apropriando-se de tecnologias na escola, busca o aprendizado pela prática em conjunto voltada para o desenvolvimento, entre os sujeitos, de uma aproximação produtiva e da liberdade como aspecto fundamental. Tais pontos constituem a concepção freinetiana de cooperação (Freinet, 1998).

A apresentação dos cenários descritos até aqui sugere que a cooperação freinetiana - por seu teor produtivo compartilhado, espontâneo e aproximativo poderia possuir consonâncias com o exercício da podosfera nacional. Em vista disso, surgiu a necessidade de investigar-se a hipótese levantada. Tal exame é pertinente, pois, caso fosse constatada uma relação de similaridade entre a cooperação em Freinet e as ações da podosfera brasileira, tornar-se-ia possível que estas últimas fossem apropriadas pela educação formal. A aludida apropriação poderia proporcionar iniciativas que trouxessem à educação formal práticas educacionais cooperativas de 
uso do podcast, norteadas pela ótica de Freinet. Nessa circunstância, somar-se-ia às possibilidades de uso educacional do podcast uma abordagem particular.

O campo de estudos educacionais da aludida tecnologia conta com trabalhos como o de Barros e Menta (2007), que versa sobre uma experiência pedagógica que deixa explícita a busca pela formação de alunos críticos por meio do estímulo para que estes atuem produtivamente, realizando até mesmo expressões artísticas; bem como os estudos de Cardoso Júnior et al. (2012, p. 9), que, por meio do podcast, buscam estimular novas formas de expressão para alunos com necessidades educacionais especiais, em uma experiência na qual tal tecnologia prestou-se a "estreitar os laços entre os públicos imediatos da escola (funcionários, pais, alunos)”.

Contudo, a área que investiga as apropriações pedagógicas do podcast detém-se, muitas vezes, em pesquisar tal tecnologia a partir de experiências pedagógicas que reproduzem práticas tradicionais da sala de aula, ações pouco atentas para dispor aos sujeitos um papel ativo em práticas produtivas. Um exemplo desses estudos é a experiência realizada por Aguiar, Carvalho e Maciel (2009), em que se abordam trabalhos estudantis em grupo sem, contudo, desenvolver a natureza e as motivações dessa ação conjunta, ou mesmo o estudo de Jobbings (apud Paula; Sobrinho, 2012, p. 4), que aponta o uso do podcast voltado para a difusão de tutoriais e instruções aos alunos. Outro exemplo que segue a linha supracitada trata-se da investigação empírica de Moura e Carvalho (2006, p. 156), na qual é utilizado um podcast para reproduzir as exposições docentes, em um programa cujo intuito é levar "os alunos do ensino nocturno e os alunos que por razões várias não vão à escola, a acompanhar os conteúdos curriculares da disciplina de Português". Não se nega a importância educacional de tais usos do podcast; todavia, a investigação acerca de novos modos de apropriação de tal tecnologia para a educação formal poderia contribuir - ainda mais - para a ampliação da esfera educativa do podcast.

A busca por tal acréscimo constitui o objetivo do presente artigo, oriundo da tese Podcast na educação brasileira: natureza, potencialidades e implicações de uma tecnologia da comunicação (Freire, 2013b). Serão investigadas aqui alternativas para as abordagens do podcast que reproduzem práticas tradicionais da educação formal. Para isso, partir-se-á da análise que buscará investigar possíveis relações entre a cooperação freinetiana e as práticas ocorridas na podosfera brasileira. Desse modo, caso sejam verificadas consonâncias entre tais esferas, será possível, em seguida, desenvolver analiticamente um alicerce para futuros experimentos empíricos, na educação formal, do uso de podcast tomando-se por base o referencial cooperativo freinetiano.

Para a efetivação do objetivo proposto, inicialmente serão desenvolvidos os aspectos teóricos e metodológicos da presente pesquisa. A tecnologia do podcast será apresentada, em um primeiro momento, buscando situar o leitor sobre o tema tratado. Será definido posteriormente o conceito de "cooperação" que norteia este artigo. Em seguida, será apontado o corpus documental utilizado na investigação corrente, apresentando-se a metodologia das observações realizadas, bem como a origem das entrevistas que se inserem na base empírica do estudo em curso.

Definidos os parâmetros citados, será realizada uma análise da podosfera nacional para investigar suas relações com a noção de cooperação vista à luz de Freinet. 
O exame cooperativo da podosfera servirá para o levantamento das motivações dos sujeitos pertencentes a tal esfera produtiva, de modo que se verifique se estas apresentam consonância com a força motriz do trabalho na cooperação freinetiana: o interesse autônomo e a aproximação laboral fraterna. Também serão investigadas as implicações educacionais advindas da podosfera nacional e os parâmetros produtivos de tal trabalho em conjunto, os quais terão sua constituição examinada com base em uma relativização ao pensamento de Freinet.

Os procedimentos descritos oferecerão subsídios para o desenvolvimento de uma reflexão voltada para a compreensão do podcast escolar por meio de uma visão cooperativa oriunda das investigações realizadas.

\section{A TECNOLOGIA PODCAST}

De um ponto de vista técnico, não seria inadequado afirmar que o podcast trata-se de "um processo mediático que emerge a partir da publicação de arquivos áudio na internet" (Primo, 2005, p. 17). Embora existam podcasts destinados apenas à veiculação de músicas, a maioria daquelas produções realiza-se por meio de falas dos participantes, promovendo exposições de conteúdos, relatos de acontecimentos, bate-papos ou debates informativos sobre temas os mais diversos.

Além de poder ser descarregado como qualquer outro arquivo, clicando-se em um link postado em site ou blog, o podcast também propicia uma recepção periódica de modo automatizado por meio de um sistema de Feed $R S S .{ }^{6}$ A miniaturização dos dispositivos de áudio, bem como a incorporação de funções de tocador de MP3 em telefones celulares, associa a gravação sonora e execução do podcast a diversos aparelhos, além de possibilitar sua escuta em inúmeras situações e momentos do dia a dia. Em vista dos fatores descritos, a produção nessa tecnologia apresenta um teor facilitado. Afinal, para a realização de um podcast

[...] basta ao produtor possuir um computador de capacidade média, fone de ouvido ou caixas de som no seu PC, um microfone (de preço bastante reduzido em modelos mais simples, girando em torno de $\mathrm{R} \$ 10)$, um programa de gravação e edição de áudio, como o Audacity e uma conexão com a internet de velocidade média. (Freire, 2010, p. 114)

Os softwares necessários para a realização dos programas também são simples e, alguns deles, gratuitos (Cruz, 2009, p. 76). A viabilidade financeira da produção em podcast ressalta-se também pela possibilidade de sua disponibilização on-line sem custos. Isso ocorre em razão da presença de diversos serviços gratuitos de armazenamento automatizado de podcasts.

6 Abreviação de really simple syndication, que significa "distribuição realmente simples". Trata-se de uma ferramenta que permite a assinatura de conteúdos digitais periódicos, os quais são recebidos quando de sua atualização. A funcionalidade é utilizada costumeiramente para a assinatura de blogs e podcasts. 
Em vista do exposto, o podcast desvela facilidades de produção e acesso justificáveis de sua larga disseminação, além do oferecimento de novas possibilidades práticas, base dos potenciais e implicações educativas dessa tecnologia. Nesse contexto, apesar dos aspectos técnicos de vinculação a arquivos digitais de áudio, caso se parta da consideração da apropriação pedagógica do podcast, incluindo sua versão voltada para os deficientes auditivos, é possível entender essa tecnologia além de seu foco técnico. Por essa ótica, o podcast é caracterizado não como uma tecnologia de áudio, mas de oralidade (Freire, 2013a, p. 42).

\section{ASPECTOS METODOLÓGICOS}

\section{O CONCEITO DE “COOPERAÇÃO” EM FREINET}

A cooperação será entendida neste texto com base na concepção do professor francês Célestin Freinet. Contudo, cabe salientar que a utilização da perspectiva freinetiana não corresponde à destituição de outras visões acerca da cooperação, mas consiste na opção pelo seguimento de um norteador relevante para o desenvolvimento de uma educação ativa, baseada na produção daqueles que nela se envolvem.

Anterior à elaboração de sua perspectiva de cooperação, Freinet realizou na pedagogia que leva seu sobrenome a retomada educativa de uma palavra que, apropriada por perspectivas mercantis, representa uma acepção ligada quase que estritamente à aquisição financeira e material. Trata-se do termo "trabalho".

Para Freinet (1998), ligado à tradição marxista, o trabalho suplanta a ideia de estrito objeto produtivo voltado para o escambo financeiro. Em suas concepções pedagógicas, o autor concebe a noção de trabalho como oposta a uma perspectiva de "tarefa obrigatória, que nos sujeita, da qual nos esquivamos tão logo seja possível, mediante más ações, se necessárias [...]” (idem, p. 333). O trabalho é entendido pelo autor como um exercício de vida, movimento inerente a homens e mulheres em relações efetivadas por meio de uma atmosfera fraterna, generosa e justa. Emerge nesse contexto um referencial no qual a noção de "aprender a fazer fazendo" adquire ares centrais para o crescimento educativo. Por esse norteador, o trabalho compartilhado pelos sujeitos constitui, por servir como esfera de convivência, um aspecto basilar na formação educativa dos indivíduos. Assim, chega-se à noção cooperativa de Freinet (idem), que compreende o compartilhamento espontâneo do trabalho educativo.

A cooperação freinetiana elenca o trabalho como instância de encontro dos sujeitos para a ação de aprender, rejeitando o recebimento de uma educação preconcebida em manuais escolares, "ciência fria" (Freinet, 1975, p. 54), em favor do exercício em conjunto da elaboração laboral do conhecimento. Como sujeitos envoltos nesse processo, os indivíduos apropriam-se criticamente das informações disponíveis envoltos em uma atmosfera relacional produtiva, pela qual podem tatear o mundo, examinando-o por meio de seus objetos, locais e meios expressivos.

A perspectiva esclarecida é demonstrada pela pedagogia Freinet em diversas práticas como aulas-passeio, que levam os alunos ao encontro direto com lugares sobre os quais, anteriormente, apenas poderiam abstrair; correspondência interescolar, promotora do contato aberto com realidades de colegas que estejam distantes por meio da troca de cartas; uso pedagógico de tecnologias, o qual oferece o aprendizado 
ao indivíduo pelo tateamento produtivo livre na elaboração de conteúdos por meio de tecnologias; texto livre, viabilizador da expressividade liberta dos sujeitos, o que ocorre mediante o oferecimento aos alunos da possibilidade de realizações produtivas em diversos meios - cinema, jornal, desenho, áudio, entre outros (idem,1977).

\section{METODOLOGIA DE OBSERVAÇÃO DA PODOSFERA}

A observação da podosfera brasileira, a qual forneceu subsídios às análises do corrente estudo, foi realizada durante a elaboração da tese da qual se origina este artigo. A pesquisa de doutoramento aludida consiste em um trabalho que buscou prover as bases teóricas iniciais a um pensamento educativo articulado do podcast.

No delineamento temático do presente artigo, a efetivação do olhar lançado à podosfera deu-se por meio de uma observação participante, segundo os parâmetros definidos por Peruzzo (2006, p. 125). O procedimento foi viabilizado pela audição, por parte do pesquisador, de cerca de cinco centenas de programas em podcast. A partir disso, ocorreu a participação daquele estudioso nos grupos de audiência do podcast. Vale salientar que o foco do olhar descrito direcionou-se aos podcasts "não comerciais", referidos neste texto apenas pelo termo podcasts. Essa decisão foi tomada em razão de tais produções constituírem a principal modalidade de uso dessa tecnologia no país (Freire, 2013b, p. 20).

A seleção das fontes de observação aqui realizada não se centralizou na busca por representatividade estatística, mas esteve "mais ligada à significação e à capacidade que as fontes têm de dar informações confiáveis e relevantes sobre o tema de pesquisa" (Duarte, 2006, p. 68). Desse modo, foi feito uso, segundo a classificação de Duarte, de "seleção intencional", na qual "o pesquisador faz a seleção por juízo particular, como conhecimento do tema ou representatividade subjetiva" (idem, ibidem).

Foram ouvidos produtores relevantes da podosfera brasileira, idealizadores de podcasts de grande audiência ou de importantes iniciativas na área. Essa escuta ocorreu por meio da audição de vários depoimentos expressos em podcasts por seus próprios realizadores, bem como pela realização de uma entrevista com Beatriz Kunze, que produziu o primeiro podcast para surdos do país. Tal interlocução foi realizada a distância, por meio do envio de perguntas por $e$-mail e respostas via áudio digital gravado por Kunze.

Foram utilizados, ainda, os dados colhidos na dissertação (Freire, 2010) que precedeu a tese que origina este artigo. Naquele estudo de mestrado, foram escutados dez ouvintes do "Guanacast", podcast do site Guanabara.info, projeto educativo não escolar que contém, além de podcasts, blog e aulas em diversos formatos (web, videoaula, em formato flash, entre outros) voltados para conteúdos de informática. A escolha pela escuta dos participantes de tal projeto justifica-se pela relevância educativa deste na podosfera nacional, em vista de aquela iniciativa contar com participação massiva de usuários, que a buscam movidos pelo interesse espontâneo,

7 Disponível em: <www.guanabara.info/tag/guanacast>. Acesso em: 22 jan. 2013. 
dado que não contam com nenhum tipo de certificação escolar. Já na metodologia das entrevistas com os ouvintes dos "Guanacast",

a coleta de dados, do tipo primário, foi realizada de forma não presencial, por programas de mensagens instantâneas, e-mail e conversa on-line por áudio, através da técnica de entrevista semiaberta com usuários desse site. [...] A seleção das fontes foi realizada por conveniência, ou seleção acidental como classificado por Duarte (2006, p. 69). [...] Considerando a viabilidade, trabalhamos com interlocutores do tipo informante-padrão encontrados no canal de chat MSN do Guanabara.info - o "amigos Guanabara.info" - pelos comentários nas postagens de podcast e também pela comunidade do Orkut "Guanabara.info podcast". (idem, p. 13, 20, 22)

A partir do corpus levantado pelos procedimentos aqui expostos, foi possível realizar o levantamento das motivações, das estratégias produtivas e dos objetivos que perpassam o universo produtivo dos podcasts brasileiros.

\section{AS RELAÇÕES E PRÁTICAS PRODUTIVAS DA PODOSFERA BRASILEIRA}

A observação da podosfera nacional aqui empreendida indicou que esta detém, em seu entorno, múltiplas realizações, agregadoras de texto, imagem e bipertexto. A associação de tal tecnologia a blogs acaba propiciando a junção dos diversos elementos citados. Em vista de tal multiplicidade, as demandas dos podcast tecnicamente mais elaborados da podosfera nacional constituem-se, em geral, das seguintes ações: levantamento de pauta; realização de pesquisa sobre o tema a ser abordado; gravação; edição; elaboração do texto sinopse da postagem; montagem de imagens para ilustrar as postagens dos programas; reunião de links relativos aos temas abordados; organização das discussões via comentários e cessão de feedback aos ouvintes; e gerenciamento técnico da distribuição dos arquivos digitais (servidores). É necessário ressaltar que as necessidades apresentadas relacionam-se a podcasts detentores de maior sofisticação técnica. Portanto, de modo algum se consideram todos esses fatores como imprescindíveis à realização de podcasts.

Uma vez percebida a extensão de fatores a serem gerenciados, conclui-se que há uma significativa dificuldade na produção individual de um podcast caso busque-se atender à realização, com esmero, de todos os parâmetros apresentados. ${ }^{8}$ Por esse motivo, a prática corriqueira dada na podosfera brasileira é constituída de

8 Cabe salientar que a afirmativa posta não nega a possibilidade de individualização produtiva do podcast. Destacam-se simplesmente as proporções alargadas das demandas produtivas quanto a realizações que busquem atender, com alto grau de qualidade técnica, diversos aspectos relacionados à criação de um podcast. Isso não implica impossibilidade do desenvolvimento tanto de programas competentes que não atendam muitos dos aspectos citados quanto de produções individuais que possuam um alto cuidado técnico, a exemplo do podcast "Escriba Café", feito por um único produtor. 
uma associação entre diversos realizadores, a fim de dar conta das demandas produtivas múltiplas de suas produções. Dessa forma, a efetivação das diversas tarefas necessárias à produção e publicação de um podcast nesse cenário normalmente é compartilhada por diversos sujeitos. Essas necessidades costumam ser especialmente árduas para um desenvolvimento aprofundado do processo de edição, o qual poderá prover aos programas um ritmo mais dinâmico.

Observa-se no contexto apresentado uma série de meios que viabilizam tecnicamente a aproximação entre os sujeitos para a realização conjunta de podcasts, como programas de mensagens instantâneas, redes sociais, Twitter, entre outros. Outra forma técnica que pode ser utilizada para contrapor um distanciamento entre os usuários é o chat com voz realizado por meio de softwares como o Skype, ${ }^{9}$ programa amplamente utilizado para a gravação de podcasts.

Diante do cenário em vista, o estudo aqui posto necessitou compreender se as ações em conjunto e a disposição das tecnologias supracitadas resultam, na podosfera brasileira, em efetiva cooperação, esta entendida com base no referencial eleito neste texto. Necessitou-se observar, para a reflexão proposta, casos representativos do modo de produção usual da podosfera do Brasil. Nesse cenário,

[...] existem Podcasts que são produzidos por dois ou mais internautas que tenham um interesse comum por determinado assunto, muitas vezes abordando temas específicos que não estariam sendo veiculados por meios convencionais de transmissão radiofônicas. (Medeiros, 2006, p. 4)

A forma de produção aludida repercutiu no depoimento de Juca D’Angelo, realizado durante sua participação no episódio oito da segunda temporada ${ }^{10}$ do podcast "Tatoscopio". ${ }^{11}$ D'Angelo (2012) descreve nessa fala sua entrada no podcast "Rapaduracast", afirmando:

Rolou uma brincadeira muito legal que o Maurício ${ }^{12}$ faz de vez em quando, que é o cabine coletiva, ${ }^{13}$ e eu participei do primeiro. Ele falou - eu vi no Twitter: "olha, quem quiser trocar uma ideia sobre 'A Origem', ${ }^{14}$ eu vou tá domingo. Anotem meu skype e entra que a gente troca”. Aí eu fiquei super empolgado porque pensei "Porra, finalmente vou passar do modo passivo para realmente

9 Disponível em: <www.skype.com>. Acesso em: 22 jan. 2013.

10 Alguns podcasts numeram suas edições por temporadas, zerando, ao final de cada ano, a contagem dos episódios para, no ano posterior, reiniciar seguido da indicação do número da nova temporada em vigência.

11 Disponível em: <wergeeks.net/2010/09/16/tatoscopio-com-marcelo-salgado>. Acesso em: 22 jan. 2013."

12 É feita referência a Maurício Saldanha, um dos realizadores do "Rapaduracast".

13 Iniciativa do site Cabine Celular. Por meio dela, os ouvintes reúnem-se on-line com os produtores do site para discutir filmes e assuntos relacionados ao cinema. Mais informações em: <www. cabinecelular.com.br>. Acesso em: 22 jan. 2013.

14 Filme americano de ficção científica lançado em 2010. A produção notabilizou-se pelas diversas possibilidades de interpretação da trama, gerando, assim, discussões acaloradas, principalmente na época de sua estreia nos cinemas. 
ter uma troca, de inda e vinda". Então, fiquei empolgadão, vi o filme para trocar essa ideia - claro que eu tava afinzão de ver o filme, mas eu vi no domingo para poder conversar com ele. Fiquei amarradaço, amei o filme e voltei empolgadão. Aí o nosso papo foi tão maneiro que ele falou "ô, cara, manda o áudio" e tal. E aí acabou que rolou. Então, foi assim. Tô lá, troco uma ideia muito maneira. ${ }^{15}$

Em consonância com as observações de Medeiros, o depoimento colhido indica que há na podosfera nacional uma aproximação entre indivíduos motivada pelo compartilhamento de interesses em comum. Observa-se, ainda, que o encontro descrito culminou no estabelecimento de uma parceria produtiva entre o ouvinte e os realizadores do programa do qual aquele era fã, um dos maiores podcasts brasileiros.

Tal vontade espontânea de usuários da podosfera em tornar-se mais próximos uns dos outros a partir de um entorno produtivo em comum demonstrou centralizar as motivações produtivas observadas. Esse fenômeno pôde ser verificado em depoimentos como aquele do podcaster Pedro Henrique Nunes Dias Junior, conhecido na podosfera brasileira pelo pseudônimo de "Ninja Inimigo". Ao falar sobre suas motivações ao produzir o podcast sobre videogames Baixo, frente, soco, Pedro Henrique Dias esclarece:

[...] a gente quer falar o que a gente pensa e conhecer pessoas. Porque é muito difícil, hoje em dia, conhecer pessoas que gostem dessas mesmas coisas e queira discutir, queira conversar. Então, o maior prêmio do podcast pra mim é conhecer pessoas. Então, eu não vou mudar uma atitude ou outra que eu tenha no podcast pra poder monetizar, pra poder botar em um portal, pra poder fazer outras coisas. (Castro; Siqueira, 2012)

A fala do podcaster veicula uma inversão de prioridades em comparação aos critérios normalmente utilizados nos meios comerciais, como rádio eTV. Enquanto nesses meios a obtenção de lucro financeiro costuma guiar a formulação de programas, modificações em elencos e grades de programação, os norteadores explicitados por Dias centralizam-se em seu desejo de expressar a leitura de mundo particular que possui e buscar outros que compartilhem tal perspectiva. Assim, o distanciamento de motivações pecuniárias acaba por enfatizar os supracitados intuitos expressivos e sociais das produções. Tal observação, quando relativizada à constatação de que a maior parte da podosfera nacional é composta por programas que não geram lucro financeiro (Freire, 2013c, p. 104), indica que motivações como a citada por "Ninja Inimigo" constituem a força motriz que leva à produção de significativa parcela dos podcasts brasileiros. Em muitos destes, também foi observada a ocorrência da ação dos ouvintes em instâncias produtivas, como a postagem de notícias, envio de artes para o blog de um podcast, moderação de fóruns relativos às produções, entre outras práticas afins, como visto no entorno produtivo do Guanabara.info (Freire, 2010, p. 47-48).

15 Objetivando manter o teor de oralidade do texto exposto, optou-se por manter as gírias e as fugas da norma culta presentes no original. 
Tal estabelecimento de ações produtivas conjuntas, em favor de um objetivo em comum, foi igualmente observado na dimensão inclusiva da podosfera. Isso ocorreu na medida em que se constatou que o processo de transcrição, desenvolvido na elaboração dos podcasts para surdos, ocorre geralmente de forma compartilhada desde o início desse tipo de produção, remissivo ao episódio 94 do podcast "Podsemfio". ${ }^{16}$ O programa discorreu sobre tecnologias voltadas para os deficientes auditivos. No que diz respeito ao processo de transcrição desse podcast, sua produtora afirma:

No próprio post [...] eu perguntei: olha, eu estou a fim de fazer isso mas não posso transcrever tudo isso sozinha. Alguém topa participar, transcrever em equipe? Aí um grupo de dez pessoas mais ou menos se manifestou. Eu sempre converso com todos eles por $e$-mail e a gente vai revezando, cada um vai transcrevendo um podcast. (Kunze, 2012, s.p.)

Igualmente, constatou-se que esse tipo de ação conjunta ocorre nos podcasts para surdos elaborados pelo programa "Dispersando". ${ }^{17}$ Assim, o modo de funcionamento desvelado pelas observações e reflexões realizadas indica que a produção conjunta sustenta uma significativa parte da podosfera nacional. Nessa forma de realização, percebeu-se que as múltiplas demandas de um podcast tecnicamente sofisticado acabam atendidas por um trabalho oriundo da iniciativa espontânea de sujeitos que agem, mutuamente, em favor dos programas de sua predileção. Dessa forma, tal exercício transcorre envolto em uma atmosfera laboriosa. Nesta, o trabalho transforma-se em um mote para a aproximação dos sujeitos, reunidos, pela interseção de um universo em comum, para práticas produtivas em manifestações tecnológicas orais, escritas e imagéticas em meios digitais.

Diante dos aspectos expostos, constata-se que uma significativa parcela da apropriação nacional do podcast possui uma conformidade com a cooperação preconizada pelo pensamento do professor Freinet, estudioso partidário da superação de práticas estritamente coercitivas para o alcance da alegria do trabalho educacional, desde os níveis escolares iniciais (Freinet; Balesse; Barbosa, 1977, p. 43-47). Tal relação de consonância é realçada na medida em que o olhar aqui lançado percebeu que a podosfera materializa a superação da coerção produtiva nas diversas formas desta ação. Tais aspectos podem ser exemplificados com a forma de coerção financeira, que leva à omissão de posicionamentos contrários aos patrocinadores, ou mesmo à coerção institucional. Esta, no percurso de realizações midiáticas ligadas a veículos da respectiva área, imputa restrições ao conteúdo de programas de acordo com as determinações de empresas que detêm tais produções (Freire, 2012, p. 9).

A superação da perspectiva coercitiva nos podcasts deve-se à constatação de que, nos processos produtivos da podosfera brasileira, diversos sujeitos, apartados de qualquer perspectiva de relevante lucro financeiro, contrapartida institucional (certificados, diplomas) ou mesmo profissional, emprestam seu tempo para atuar em conjunto com outros que produzem um podcast cujas abordagens e temáticas

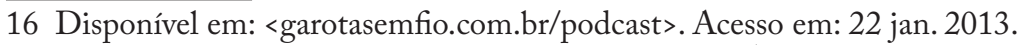

17 Disponível em: <scienceblogs.com.br/dispersando>. Acesso em: 22 jan. 2013. 
sejam atraentes. A atmosfera cooperativa demonstrou, dessa forma, sua presença nas ações referidas, em virtude da larga disposição dos envolvidos para realizar tarefas, mesmo que estas demandem muito tempo e comprometimento, e, ainda assim, resultem em pouca visibilidade de seus realizadores, por dizerem respeito a programas com um grupo restrito de ouvintes. Essa conduta foi percebida na experiência do podcast "Fenixdown", ${ }^{18}$ distante de figurar entre as maiores audiências do país. Os produtores do programa em questão, no episódio 19B, ${ }^{19}$ descrevem as experiências vivenciadas na construção do podcast:

Fernando: - A coisa legal que a gente tem dos colaboradores porque é tudo gente ajudando de boa fé, sabe? É tudo "pé rapado" tanto quanto a gente. A gente não ganha nada e eles também não ganham nada. Mas é um pessoal que, pô, quando a gente precisou fez uma chamada, teve muita gente que se candidatou, nem todo mundo ficou.

Diego: - A primeira chamada que eu fiz para colaborador, para ajudar na edição - não era pra participar do podcast, era pra ajudar na edição - deu 40 pessoas. (Castro; Siqueira, 2012)

Observa-se, na experiência descrita pelos podcasters citados, um modo de relação produtiva que repercute as palavras de Freinet (1998, p. 335) quando estas asseveram que "a verdadeira fraternidade é a fraternidade do trabalho". O caso narrado anteriormente também ressalta a importância do compartilhamento de um interesse temático em comum para o fomento da aproximação laboral. Nessa direção, as chances de compartilhamento temático na podosfera são acrescidas pela grande amplitude de assuntos e posicionamentos abordados (Freire, 2013c, p. 119). Além disso, a vasta dimensão de temas da podosfera é potencializada pelas possibilidades de nela sujeitos expressarem-se de forma não nominada. Isso ocorre na medida em que

O podcast tem no parcial anonimato que propicia a seus produtores outro mote para uma maior liberdade expressiva, direcionada àqueles Sujeitos que temeriam represálias ou constrangimentos se tivessem de expor seus posicionamentos e valores nominalmente. (Freire, 2013b, p. 273)

A podosfera também demonstrou ser constituída de uma parcela de usuários que costumam assumir uma postura ativa na lida com informações. Um exemplo de tal posicionamento esteve na resposta do público diante da atividade "Verdade ou mentira?", realizada pelo podcast "Guanacast". A iniciativa apresentada remete-se a uma prática oriunda da Rádio Educativa, a qual, como aponta Consani (2007), presta-se a "trabalhar de maneira lúdica com a questão da credibilidade na mídia,

18 Disponível em: <fenixdown.com.br/category/podcast >. Acesso em: 22 jan. 2013.

19 Alguns podcasts utilizam letras após os números para expressar os episódios que foram divididos. 
que, no rádio, está intimamente ligada aos formatos do gênero jornalístico" (idem, p. 152). São veiculadas na atividade em questão notícias de caráter peculiar, todas aparentemente pouco críveis, sendo apenas algumas verdadeiras. Os leitores são estimulados por meio daquele jogo a realizar pesquisas a fim de discernir quais notícias seriam verdadeiras e quais se tratariam de informações falsas.

O exercício propiciado pela atividade citada, muito além da brincadeira que a organiza, direciona-se para o aprimoramento da prática de formação do leitor por meio da necessidade de realização de pesquisas e apropriação crítica dos alunos quanto aos materiais encontrados on-line. A recepção ativa dos ouvintes do "Guanacast" diante do "Verdade ou mentira?" é ilustrada pela fala de uma de suas participantes, exposta no depoimento apresentado a seguir:

Entrevistador diz:

Você participou das atividades propostas nos episódios 49 e 54 - Verdade ou Mentira? [...] Por quê?

Entrevistada D diz:

Ahh $\operatorname{sim}[\ldots]$

Entrevistador diz:

Mas o que vocÊ $\hat{E}$ acha legal nesses tipos de episódio? não dá trabalho fazer as pesquisas, ainda mais que nem nota você vai receber pra ter aquele trabalho todo?

Entrevistada D diz:

haushausa

ah mas se for algo interessante

eu acredito que nao importe o valor ou o reconhecimento

vai ser algo que eu vou ta atraz de saber... algo que me interesse

xato seria se o assunto nao me interessase

ai sim eu iria reclamar'

[...]

se for algo interessante vale o esforço

algo que eu sei que depois de pesquisado

eu tenha certeza que vou aprender

(Freire, 2010, p. 49)

Diante da observação sobre os diversos aspectos do desenvolvimento produtivo concernentes à podosfera nacional, percebe-se, nessa instância, um cenário formado por uma significativa parcela de sujeitos abertos ao trabalho compartilhado, livre e educacional nas diversas etapas constituintes das relações laborais vivenciadas. Em vista do exposto, constata-se a consonância entre o contexto descrito e a cooperação freinetiana. Tal percepção leva à caracterização da podosfera brasileira como um âmbito de exercício da cooperação, segundo Freinet. Todavia, cabe salientar que as análises realizadas tratam, como já dito, de uma parcela da podosfera nacional, 
de modo que não se conclui que todas as práticas daquela esfera alcancem o teor cooperativo freinetiano, mas, sim, que aquela instância abriga práticas de cooperação pelo referencial de Freinet.

A conclusão construída possui uma importante implicação educacional, dado que, sendo a podosfera brasileira âmbito de exercício da cooperação freinetiana via podcast, como é possível pensar a apropriação de tais práticas na educação formal, a fim de ampliar as apropriações educativas daquela tecnologia? A busca por essa resposta será realizada pela reflexão que tomará lugar a seguir.

\section{PODCAST COOPERATIVO ESCOLAR}

A presente análise buscará desenvolver parâmetros para subsidiar o estabelecimento de projetos que utilizem o podcast na educação formal tomando-se por base uma perspectiva cooperativa freinetiana. Para isso, será desenvolvida uma proposta que aglutinará tal cooperação à natureza produtiva da podosfera nacional. A princípio, ressalva-se que os direcionamentos elaborados buscarão constituir referenciais, não regras. Em vista disso, caberá aos profissionais da educação relativizar a aplicação desses norteadores ao contexto vivenciado.

Inicialmente, é importante esclarecer que, na contextualização escolar do exercício cooperativo do podcast nacional, as constatações de Moura e Carvalho (2006) caracterizam-se como um importante aporte. Os autores apontam que o podcast necessita de sujeitos motivados para o desenvolvimento de práticas educacionais relevantes (idem, p. 89), razão pela qual, na apropriação cooperativa do podcast pela educação formal, percebe-se ser fundamental o estímulo ao protagonismo do estudante, para fomentar neste o desenvolvimento da motivação.

Pelo seguimento do norteador proposto, a apropriação cooperativa do podcast na educação formal poderia servir à revelação de propensões particulares dos estudantes. Mostrar-se-ia importante para isso o seguimento de um modo de trabalho livre, no qual a distribuição dos diversos aspectos produtivos nas realizações fosse pautada pela adequação às aptidões particulares de cada sujeito, bem como aos seus anseios expressivos. Desse modo, remontar-se-ia à pedagogia freinetiana, marcada, nos moldes do texto livre, pela escolha aberta entre diversos modos expressivos.

No entanto, o teor de espontaneidade das práticas propostas institui uma demanda ausente em ambientes escolares fortemente coercitivos, a qual será descrita a seguir. $\mathrm{Na}$ abordagem das necessidades citadas, é sensato referir o risco perene de surgimento de conflitos entre os alunos, em virtude da ausência da determinação, pelo professor, dos papéis ocupados pelos estudantes. Assim, situações como o desejo por exercer uma determinada função, já ocupada por um colega, ou a sensação de estar trabalhando mais que os demais tenderiam a gerar momentos de embates e frustrações, possivelmente removendo o interesse pela ação cooperativa e, em vista disso, distanciando o estudante da apropriação educativa de tal ação em conjunto.

Contudo, o risco apresentado ofereceria uma oportunidade ímpar para o trabalho de formação do cidadão pela educação formal. Partindo-se das concepções de Freinet, a administração das situações relatadas e afins poderia ocorrer a partir de uma resolução democrática, pautada na decisão coletiva dos alunos. Seria 
possível, para isso, construir um desenvolvimento laboral guiado "por votos de mão levantada" (Freinet, 1974, p. 21), no qual a realização de assembleias para votação de questões pertinentes tornar-se-ia uma ação periódica. Além disso, o levantamento de críticas, sugestões e elogios na produção em questão poderia apropriar-se das ideias de Freinet por meio de ações em que "através de bilhetes, os alunos seriam estimulados a escrever, individualmente, suas opiniões na forma de 'eu proponho', 'eu critico' e 'eu felicito"' (Freire, 2010, p. 93). Dessa maneira, seriam reunidas práticas para a organização das relações produtivas vivenciadas, auxiliando no alcance de um desenvolvimento mais lúcido e bem elaborado por parte dos alunos.

No seguimento do caminho cooperativo traçado, a escolha da temática a ser abordada poderia compreender um importante momento na elaboração de um podcast escolar na perspectiva aqui elencada. Essa concepção advém do papel central que o tema abordado possui no desenvolvimento da motivação para os sujeitos cooperarem no entorno de um programa, como constatado na análise da podosfera nacional. Portanto, seria positivo que a decisão temática ocorresse resultante de discussão entre os alunos, a fim de que haja predileção por temas inseridos no universo de interesses afetivos/cognitivos em comum dos sujeitos.

Nesse exercício, caberia ao professor um papel importante no estabelecimento de situações propícias para a expressão dos alunos. Para efetivação de tais circunstâncias, o docente necessitaria de colaborar com a criação de condições para que se faça ouvir a fala dos estudantes calados. Igualmente, necessitaria dispor de sensibilidade na observação das razões que possivelmente levariam alguns alunos a não se inserirem no processo, algo que costuma ocorrer por diversas razões: timidez, desinteresse, temor por rechaços. Considerando este último fator, seria válido que o professor administrasse a utilização de recursos de emissão de opinião não nominada, de modo a fazer uso, na educação formal, dos potenciais de anonimato vistos na podosfera nacional para estimular expressões normalmente omitidas. A relativização de tais pontos à educação formal poderia ocorrer pelo uso, nas decisões relacionadas ao podcast escolar, de votações secretas, partindo da utilização de bilhetes realizada na pedagogia Freinet.

Considerando a já desvelada importância da escolha temática para o posterior desenvolvimento cooperativo, é válido afirmar que, a fim de contemplar a maior amplitude de assuntos possível, um podcast escolar necessita tratar tanto de conteúdos curriculares quanto de não curriculares. Assim, enquanto em alguns cenários seria mais adequada a abordagem de temas extracurriculares - de modo que contemple temáticas relevantes, mas ausentes nas grades escolares -, em outras situações a prática cooperativa pelo podcast poderia propiciar uma situação adequada para o trabalho de conteúdos curriculares, auxiliando seu esclarecimento e apropriação ativa destes pelos alunos. Portanto, nos momentos de determinação temática tornar-se-ia importante também o debate sobre a escolha pela abordagem de conteúdos curriculares e/ou extracurriculares.

Determinado o tema da realização, seria positiva a apresentação, pelo professor, das demandas produtivas de realização do podcast em questão e, consequentemente, das funções que cada aluno poderia ocupar. De acordo com o contexto vigente, seria viável durante essa etapa propor aos alunos que, à semelhança da 
lida da pedagogia Freinet com objetos tecnológicos, praticassem o tateamento das diversas esferas produtivas do podcast, de modo que fossem experimentadas funções diversas para que cada um decida por aquela que mais lhe apetecer.

A observada atmosfera de respeito à liberdade de escolha da cooperação freinetiana indica ser necessário, igualmente, inserir no planejamento cooperativo do podcast a consideração daqueles que, ao final da apresentação do processo pelo professor, não manifestem desejo em participar das ações. Nesse caso, ganharia novamente importância basilar o distanciamento dos aspectos coercitivos desvelados por Paro (2010), como o estabelecimento de obrigatoriedade na participação. Em contrapartida, cabe assumir com parcimônia as distinções da educação formal ante aquela dada no cenário não institucional da podosfera brasileira, bem como reconhecer criticamente as limitações para o estabelecimento pleno das ideias freinetianas. Em vista disso, entende-se que é particular de cada docente o conhecimento aprofundado de sua turma. Assim, a esse profissional caberia decidir entre ser viável oferecer alternativas para a participação no projeto ou elaborar situações de recompensa institucional aos alunos para que participem da produção, contando com um posterior desenvolvimento de interesse pelo estudante, resultante das já tratadas características de mobilização do podcast. Tal expectativa de desenvolvimento seguinte de interesse demonstra que, no cenário motivado por recompensas institucionais, perderiam força os aspectos cooperativos da produção aqui em análise; contudo, não se encontrariam ali direcionamentos plenamente coercitivos tantas vezes vistos na educação formal, opositores dos referenciais propostos no presente estudo. Desse modo, ainda que promovesse uma intervenção significativa nas escolhas discentes, o professor evitaria reproduzir "a velha técnica do controle através da autoridade" (Freinet, 1975, p. 61).

Definida a temática em questão - os participantes e a divisão de seus papéis -, viabilizar-se-ia o avanço do projeto. Nesse andamento, a elaboração da pauta consistiria em um passo posterior. Tal etapa liga-se diretamente ao uso de tecnologias para a formação do leitor, em razão de serem necessárias pesquisas para a elaboração de qualquer pauta. A fim de que esta seja elaborada, a apropriação das informações colhidas - em livros ou na internet, por exemplo - necessitaria de seguir uma perspectiva analítica, de modo que fossem observadas tanto a validade quanto a relevância dos dados coletados. A motivação para tal aprofundamento, como constatado na podosfera brasileira, tenderia a vir, em grande medida, da apreciação dos sujeitos pelo tema tratado. Assim, ganharia novamente relevo a escolha temática do podcast cooperativo escolar.

Além disso, observou-se que ações no âmbito do podcast que busquem estimular a perspectiva de verificação de informações pelos alunos, algo visto no "Verdade ou mentira?", do "Guanacast", mostraram-se capazes de fomentar a capacidade crítica dos estudantes, na lida com as informações, durante o processo coletivo de construção de uma pauta. Em vista disso, seria válido na proposta aqui elaborada que a intervenção do professor ocorresse de acordo com o nível formativo dos alunos, considerando, para isso, a capacidade reflexiva daquele na relação com a imensidade de informações disponíveis atualmente. Nessa relação, entende-se que quanto mais formado leitor for o aluno, menor será a necessidade de intervenção docente. 
O estabelecimento de norteadores relacionados a objetivos, abordagens e duração dos programas é uma etapa igualmente importante na elaboração da pauta de um podcast cooperativo. Afinal, a determinação de referenciais auxilia na organização de programas, do que se pretende com estes e de como tais produções buscarão realizar seus objetivos.

No que se refere à determinação da duração do podcast, é necessário levar em conta pesquisas como a de Carvalho (2008, p. 189), que indica: "[...] Os alunos preferem podcasts de curta duração que se tornam mais fáceis de acompanhar e de rever, o que reforça a posição de alguns autores (Frydenberg, 2008; Lee; Chan, 2007)". Todavia, o mesmo autor ressalta que "se reconhece que a extensão depende sempre do propósito do podcast" (idem, ibidem).

Após a realização das gravações, seria natural supor que o programa já possuiria um direcionamento relativamente claro, ainda que prescindindo de seu aspecto final "pós-edição" - determinante de quais conteúdos seriam mantidos e quais acabariam removidos da produção. Assim, a edição seria constituída de etapa última na definição das características do podcast. Como observado na podosfera nacional, esse processo seria capaz de colaborar para oferecer mais dinâmica, organização e celeridade às falas. Entretanto, seria necessário observar que, de acordo com o esmero produtivo aplicado, a realização de podcasts possivelmente necessitaria de um dispêndio relevante de tempo e energia produtiva. Essa perspectiva encontra amparo nas experiências de Dias (2009), ao apresentar o estudo sobre o podcast "Era uma vez" ${ }^{20}$ Sobre a realização desse programa, o estudioso afirma:

O tempo necessário para a gravação e edição de cada um dos episódios foi, provavelmente, o maior obstáculo que tivemos de transpor. Por cada minuto apresentado, é necessário cerca de quatro vezes mais tempo só para edição e gravação. (idem, p. 91)

O extenso período que pode ser necessário para a edição de um programa torna válido que esse processo seja compartilhado por vários alunos. Portanto, em uma divisão produtiva, o arquivo poderia ser separado em duas ou três partes para a edição individual, a fim de que os estudantes interessados no processo, por exemplo, retirassem intervalos demasiados, selecionassem os trechos mais relevantes ou, em processos mais complexos, removessem hesitações nas falas e silêncios sem peso expressivo. Enquanto isso, seria viável que outros estudantes optassem por exercer as funções de pesquisa por músicas a serem inseridas no programa ou editadas para a utilização como vírgula sonora. ${ }^{21}$ Ao final, a junção do material caberia

20 Esse podcast trata-se de "um projecto direcionado para as crianças, educadores e professores do ensino escolar, primeiro e segundo ciclo. Através da narração de histórias e pequenos contos de autores portugueses, o podcast procura ser uma ferramenta educativa que potencie a aquisição de competências na área da língua portuguesa” (Dias, 2009, p. 85).

21 Som utilizado para dividir seções de um programa. 
a outro discente, grupo, ou mesmo à reunião daqueles que editaram o conteúdo inicial.

$\mathrm{Na}$ disponibilização do material oral, o uso do podcast para surdos ampliaria a prática aqui em análise, qualificando-a como inclusiva. Dessa maneira, tal aplicação remeter-se-ia aos potenciais inclusivos do podcast, já constatados por meio de diversos estudos (Bottentuit Junior; Coutinho, 2009; Cardoso Júnior et al., 2012; Pereira; Sobrinho; Geller, 2011, entre outros).

Para a realização da versão para surdos do podcast no contexto educativo formal, seria válido emular-se a conduta seguida na podosfera brasileira. A partir desse modo de trabalho, similar ao seguido no "Podsemfio", o áudio do programa necessitaria de ser dividido em diversas partes, sendo o arquivo referente a cada um desses segmentos enviado a um sujeito distinto para a transcrição. $\mathrm{O}$ final do procedimento em questão possibilitaria a reunião do material e a realização de uma revisão geral, a qual poderia ser efetivada por um dos transcritores do programa ou por alguém direcionado apenas para uma função revisora.

$\mathrm{O}$ aspecto textual também poderia ser inserido no podcast escolar para a veiculação de uma escrita de apresentação, bem como de uma sinopse na página de publicação do episódio, como visto na podosfera. Para essa atribuição, poder-se-ia estimular a atuação de alunos com boa capacidade de síntese e desenvoltura na produção textual, podendo, o docente, aproveitar para discutir aspectos referentes à escrita de forma que os estudantes pudessem compor um texto atraente para a postagem.

Ações de pesquisa também seriam exercidas posteriormente à realização do programa, partindo de um referencial que seria mais claro em virtude da ciência dos conteúdos que permaneceriam na versão final da produção. A pesquisa citada poderia aproveitar-se da abertura produtiva dos sujeitos quando em contato com podcasts na atmosfera aqui buscada. A busca supracitada prestar-se-ia ao oferecimento de links relacionados a materiais de ilustração de temas e situações expostas nas falas do podcast. Além disso, a realização de pesquisas informativas posteriores de forma meticulosa ofereceria, também via hiperlinks, conteúdos importantes para o aprofundamento dos assuntos abordados nos programas.

É perceptível, também, que a utilização na podosfera de imagens estáticas auxiliaria a referência rápida do conteúdo de um podcast em seu local de postagem, geralmente em um blog. Apropriando-se dessa prática, no podcast cooperativo escolar seria válido que alguns alunos tomassem a responsabilidade pela coleta, definição e formatação dessas imagens, cabendo àqueles discentes, ainda, a escolha da formatação daquelas figuras na postagem do podcast cooperativo.

\section{CONSIDERAÇÕES FINAIS}

A investigação das relações produtivas dadas no âmbito da podosfera nacional levou à constatação de que há uma consonância entre o exercício de uma significativa parcela desse universo tecnológico e a cooperação concebida e posta em curso por Freinet. Isso ocorreu porque a podosfera nacional demonstrou a posse de um modo de produção pautado na ação em conjunto de sujeitos motivados pelo interesse 
afetivo/cognitivo por temas pelos quais possuem apreço em comum. A partir disso, percebeu-se que se desenvolve naquele cenário uma atmosfera fraterna semelhante àquela defendida por Freinet, na qual o trabalho consiste na ação educativa de indivíduos que, ao agir coletivamente e de modo espontâneo, aprendem em conjunto a partir de uma ação marcada pela liberdade. Em vista das relações expostas, a podosfera nacional revelou ser um local de cooperação educativa.

A relação constatada viabilizou a construção de um pensamento segundo o qual a apropriação escolar da cooperação da podosfera nacional serviu para o desenvolvimento de uma visão que atualiza o referencial cooperativo freinetiano ao cenário de uma tecnologia vanguardista, remissiva à primeira década dos anos 2000. Assim, tornou-se possível a confecção de parâmetros direcionados ao norteamento de práticas, amparadas nos mais recentes procedimentos produtivos vistos na internet brasileira, que façam uso do podcast escolar para o desenvolvimento de projetos cooperativos à luz das concepções pedagógicas de Freinet.

A ótica apresentada foi sintetizada em referenciais desenvolvidos pensando uma proposta pedagógica de uso cooperativo de podcasts. Nesta, agruparam-se um conjunto de orientações que buscam motivar os alunos à tomada de uma postura ativa, aberta e de aproximação entre si no compartilhamento produtivo em pauta. Assim, a proposta de confecção de podcasts cooperativos escolares buscou desenvolver uma atmosfera livre em vista do teor de suas proposições.

Tais proposições sugerem que as atribuições de cada aluno em um podcast cooperativo sejam organizadas de modo que eles possam atuar na esfera produtiva que mais lhes apeteça. Os possíveis conflitos advindos do desejo de muitos estudantes por trabalhar em uma etapa produtiva que não contempla a participação de todos, por sua vez, foram tomados, pelos referenciais apresentados, como um possível mote para o exercício de uma educação democrática. As recomendações elaboradas indicam que as situações descritas seriam solucionadas por meio de um exercício coletivo, orientado pelas ideias de Freinet. Por tal direcionamento, a atribuição das funções produtivas seria determinada por meio de votações em sala de aula, as quais poderiam fazer uso de expressões anônimas para dar vazão a opiniões que, de outra forma, tenderiam a permanecer caladas.

O clima democrático também foi ressaltado nos referenciais elaborados, colaborando com o distanciamento de ações coercitivas na prática com podcasts. Contudo, entendeu-se que a administração de situações nas quais os alunos se oponham à participação na esfera produtiva aqui tratada poderia demandar alguma ação docente que não acatasse plenamente essa escolha dos alunos. Todavia, entendeu-se que tal ação não necessitaria de ser sinônima de uma atitude estritamente coercitiva por parte do professor, o que negaria os norteadores educacionais aqui seguidos.

Os referenciais elaborados indicaram a importância da escolha temática no âmbito produtivo tratado nesta pesquisa. Isso foi constatado em vista da observação da podosfera nacional, já que esta demonstrou que o compartilhamento do interesse afetivo/cognitivo por um tema consiste em um grande motor para o exercício cooperativo, razão pela qual se mostrou relevante que podcasts cooperativos escolares deem conta tanto de temas curriculares quanto extracurriculares. Na organização dos 
temas referidos, mostrou-se ser de grande importância a confecção de uma pauta, ação esta pela qual poderia ser fomentada uma postura de pesquisa pelos discentes.

Os processos posteriores às gravações também foram incluídos na proposta aqui construída, sendo percebidos como instâncias aptas à prática da cooperação via podcast. Nesse cenário, constatou-se que a divisão da edição seria capaz de propiciar o trabalho em conjunto para o melhoramento dos conteúdos produzidos. Tal partilha de atribuições também demonstrou a possibilidade de ser aplicada na transcrição dos programas voltados para o desenvolvimento de podcasts para surdos, inserindo, assim, as práticas orientadas pelos pensamentos aqui desenvolvidos em uma esfera educacional inclusiva.

Por fim, a confecção de conteúdos relacionados à postagem on-line de um podcast também foi apropriada como um possível âmbito de ação cooperativa. Nessas práticas, ações como a pesquisa por links de aprofundamento dos temas tratados, a confecção de imagens relacionadas aos programas e a escrita de textos de apresentação dos podcasts ofereceriam espaço para os sujeitos exercerem suas aptidões cooperativamente. Tais ações contribuiriam para a realização de um rico podcast, cujo principal acréscimo educacional seria não o conteúdo oferecido, mas as práticas que propiciariam aos sujeitos que ali trabalhariam, educando-se.

\section{REFERÊNCIAS}

Aguiar, C.; Carvalho, A. A. A.; Maciel, R. Podcasts na licenciatura em biologia aplicada: diversidade na tipologia e duração. In: Carvalho, A. A. A. (Org.). Actas do Encontro sobre Podcasts. Braga: CIEd, 2009. p. 140-154.

Andrade, A. A. M. Fragmentação e integração dos meios. [S.1.: s. n.]. Disponível em: <www. educ.ufrn.br/arnon>. Acesso em: 28 fev. 2009.

Assis, P.; Salves, D.; Guanabara, G. O podcast no Brasil e no mundo: democracia, comunicação e tecnologia. In: Simpósio Nacional ABCiber, 4., 2010, Rio de Janeiro: ECO/UFRJ.p.1-15. Disponível em: <pablo.deassis.net.br/psicolog/ABCiber2010podcast. pdf>. Acesso em: 15 ago. 2013.

Barros, G. C.; Menta, E. Podcast: produções de áudio para educação de forma crítica, criativa e cidadã. Revista de Economía Política de las Tecnologías de la Información y Comunicación, São Cristovão: SE, UFS, v. 9, n. 1, enero/abr. 2007. Disponível em:<www. eptic.com.br>. Acesso em: 15 mar. 2012.

Behrens, M. A. Projetos de aprendizagem colaborativa num paradigma emergente. In: Moran, J. M.; Masseto, M. T.; Behrens, M. A. Novas tecnologias e mediação pedagógica. Campinas: Papirus, 2000.

Bottentuit Junior, J. B.; Coutinho, C. P. Podcast: uma ferramenta tecnológica para auxílio ao ensino de deficientes visuais. In: Congresso LUSOCOM, 8., Lisboa, 2009, “Comunicação Espaço Global e Lusofonia". Lisboa: Universidade Lusófona de Humanidades e Tecnologias. Actas..., 2009, p. 2.114-2.126. Disponível em: <repositorium. sdum.uminho.pt/handle/1822/9030 >. Acesso em: 15 ago. 2013. 
Cardoso Júnior, V. S.; Ameno, H. Z. M.; Barbosa, P. L.; De Mello Vianna, G. V. G. Brincar na mídia: oficinas de Podcast e criação de blog em escola de educação especial. [S.1.]: Intercom - Sociedade Brasileira de Estudos Interdisciplinares da Comunicação, p. 1-10, 2012. Disponível em: <www.intercom.org.br/papers/regionais/sudeste2012/ expocom/EX33-1458-1.pdf>. Acesso em: 12 ago. 2013.

Carvalho, A. A. A. (Org.). Os podcasts no ensino universitário: implicações dos tipos e da duração na aceitação dos alunos. In: Actas do Encontro sobre Web 2.0. Braga: CIEd, 2008. p. 179-190. Disponívem em: <http://repositorium.sdum.uminho.pt/ bitstriam/1822/8558/F010-Carvalho\%20\%282008\%29.pdf>. Acesso em: 8 ago. 2012.

Castro, D. G.; Siqueira, F. L. Blogs de games. Podcast Fenixcast. Episódio 19, ago. 2012. Disponível em: <gamehelp.terra.com.br/fenixdown/category/Fenixcast $>$. Acesso em: 20 ago. 2012.

Consani, M. Como usar o rádio na sala de aula. São Paulo: Editora Contexto, 2007.

Cruz, S. C. O podcast no ensino básico. In: Carvalho, A. A. A. (Org.). Actas do Encontro sobre Podcasts. Braga: CIEd, 2009. p. 65-80. Disponível em: <repositorium. sdum.uminho.pt/bitstream/1822/9991/1/Cruz-2009-Enc\%20sobre\%20Podcasts.pdf >. Acesso em: 16 ago. 2012.

D’Angelo,J.TatoScópio com Juca D’Angelo. In: Podcast Tatoscópio. 2012. Disponível em: <wergeeks.net/2012/07/05/tatoscopio-com-juca-dangelo>. Acesso em: 9 ago. 2012. Dias, P. M. B. Podcast "Era uma vez...": utilização educativa. In: Carvalho, A. A. A. (Org.). Actas do Encontro sobre Podcasts. Braga: CIEd, 2009. p. 81-94. Disponível em: <repositorium.sdum.uminho.pt/bitstream/1822/10052/4/Actas\%20do\%20 Encontro\%20sobre\%20Podcasts.pdf >. Acesso em: 16 nov. 2012.

Duarte, J. Entrevista em profundidade. In: Duarte, J.; Barros, A. (Org.). Métodos e técnicas de pesquisa em comunicação. 2. ed. São Paulo: Atlas, 2006.

Freinet, C. O jornal escolar. Lisboa: Editorial Estampa, 1974. . As técnicas Freinet da escola moderna. 4. ed. Lisboa: Editorial Estampa, 1975. . O método natural I: a aprendizagem da língua. Lisboa: Editorial Estampa, 1977. A educação do trabalho. São Paulo: Martins Fontes, 1998.

1977.

.; Balesse, L.; Barbosa, A. A leitura pela imprensa na escola. Lisboa: DinaLivro,

Freire, E. P.A. Construindo um modelo de referência à participação ativa dos sujeitos em projetos educativos em ambiente on-line. 2010.214p. Dissertação (Mestrado em Educação) - Centro de Ciências Sociais Aplicadas, Universidade Federal do Rio Grande do Norte, Natal, 2010. Disponível em: <bdtd.bczm.ufrn.br/tedesimplificado/tde_arquivos/9/TDE-201012-17T072926Z-3169/Publico/EugenioPAF_DISSERT.pdf>.Acesso em: 22 jan. 2010.

.O podcast como ferramenta de educação inclusiva para deficientes visuais e auditivos. Revista Educação Especial, Santa Maria: UFSM, v. 24, n. 40, p. 195-206, maio/ago. 2011. Disponível em: <cascavel.ufsm.br/revistas/ojs-2.2.2/index.php/educacaoespecial/ issue/view/210/showToc>. Acesso em: 3 nov. 2011. 
. Distinções educativas entre rádio e podcast. Revista PRISMA.COM, Porto: CETAC.MEDIA, n. 18, p. 1-23, 2012. Disponível em: <revistas.ua.pt/index.php/ prismacom/article/view/1418>. Acesso em: 10 ago. 2013.

Conceito educativo de podcast: um olhar para além do foco técnico. Educação, Formação E̊ Tecnologias, Caparica, PT: FCT, v. 6, n. 1, p. 35-51, 2013a. Disponível em: <eft.educom.pt/index.php/eft/article/view/340>. Acesso em: 12 ago. 2013.

. Podcast na educação brasileira: natureza, potencialidades e implicações de uma tecnologia da comunicação. 2013b. 338p. Tese (Doutorado em Educação) - Centro de Ciências Sociais Aplicadas, Universidade Federal do Rio Grande do Norte, Natal.

Podcast: novas vozes no diálogo educativo. Interacçôes, Lisboa: ESES, n. 23, p. 102-127, 2013c. Disponível em: <revistas.rcaap.pt/interaccoes/article/view/2822>. Acesso em: 17 ago. 2013.

Freire, P. Extensão ou comunicação? Rio de Janeiro: Paz e Terra, 1971.

Frydenberg, M. Principles and pedagogy: The two p's of podcasting in the information technology classroom. Information Systems Education Journal, v. 6, n. 6, p. 1-10, Feb. 4, 2008. Disponível em: <www.isedj.org/6/6/ISEDJ.6\%286\%29.Frydenberg.pdf>. Acesso em: 8 ago. 2012.

Gardner, H. Inteligências múltiplas: a teoria na prática. Tradução de Maria Adriana Verríssimo Veronese, Porto Alegre: Artes Médicas, 1995.

Jоввіngs, D. Exploiting the educational potential of podcasting. Russell Educational Consultancy and Productions, 2005. Disponível em: <recap.ltd.uk/articles/podguide. html>. Acesso em: 27 out. 2007.

Kunze, B. Entrevista oral (via podcast) concedida a Eugênio Paccelli Aguiar Freire. 2012. LeE, M.; Chan, A. Reducing the effects of isolation and promoting inclusivity for distance learners through podcasting. The Turkish Online Journal of Distance Education, Eskisehir, Turquia: Anadolu University, 8, p. 85-104. 2007. Disponível em: <tojde. anadolu.edu.tr/tojde25/articles/Article_7htm>. Acesso em: 8 ago. 2012.

Medeiros, M. S. Podcasting: produção descentralizada de conteúdo sonoro. In: Congresso Brasileiro de Ciências da Comunicação, 28., 2005. Rio de Janeiro. Anais... São Paulo: Intercom, p. 1-11, 2005. Disponível em: <www.portcom.intercom. org.br/pdfs/84071885084469832222151638470992010359.pdf >. Acesso em: 14 abr. 2012.

Podcasting: um antípoda radiofônico. In: Congresso Brasileiro de Ciências Da Comunicação, 29., 2006, Brasília. Anais... São Paulo: Intercom, 2006.

Moura, A.; Carvalho, A. A. A. Podcast: uma ferramenta para usar dentro e fora da sala de aula. In: Rui, J.; BaQuero, C. (Eds). Proceedings of the Conference on Mobile and Ubiquitous Systems. Guimarães: Universidade do Minho, 2006. p. 155-158. Disponível em: <repositorio.uportu.pt/dspace/handle/123456789/491 >. Acesso em: 15 ago. 2013. PARo, V. H. Educação como exercício de poder: crítica ao senso comum em educação. 2. ed. São Paulo: Cortez, 2010. 104p. 
Paula, J. B. C.; Sobrinho, J. C. Podcasts educativos: possibilidades, limitações e a visão de professores de ensino superior. In: Simpósio Hipertexto e Tecnologias na EduCAÇÃo, 3., 2012. Anais eletrônicos..., UFPE, p. 1-21, 2012. Disponível em: <www.ufpe.br/ nehte/simposio/anais/Anais-Hipertexto-2010/JoaoBasilio\&Jeronimo-Coura-Sobrinho. pdf $>$. Acesso em: 15 ago. 2013.

Pereira, L. L.; Sobrinho, M. C.; Geller, M. T. B. Relato de experiência da utilização do podcast com deficientes visuais. RENOTE, Porto Alegre: UFRGS, v. 9, n. 3, 2011. Disponível em: <seer.ufrgs.br/renote/article/view/24870>. Acesso em: 15 ago. 2013.

Peruzzo, C. K. Observação participante e pesquisa-ação. In: Duarte, J.; Barros, A. (Org.). Métodos e técnicas de pesquisa em comunicação. 2. ed. São Paulo: Atlas, 2006.

Primo, A. F. T. Para além da emissão sonora: as interacções no podcasting. Intertexto, Porto Alegre: UFRGS, v. 2, n. 13, p. 1-23, jul./dez. 2005. Disponível em: <www.lume. ufrgs.br/handle/10183/26568>. Acesso em: 14 mar. 2011.

Sampaio, R. M. W. F. Freinet: evolução histórica e atualidades. São Paulo: Scipione, 1994.

Teixeira, A. Pequena introdução à filosofia da educação: a escola progressiva ou a transformação da escola. São Paulo: Companhia Editora Nacional, 1971.

\section{SOBRE O AUTOR}

Eugênio Paccelli Aguiar Freire é doutor em educação pela Universidade Federal do Rio Grande do Norte (UFRN). Professor da mesma instituição.

E-mail: paccellifreire@gmail.com 